\title{
Forelle blau und danach ein Videospiel
}

\author{
Dr. med. \\ Dirk Einecke \\ Chefredakteur
}

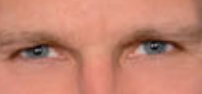

HERZGESUNDER FISCH

\section{Auf die richtige Zubereitung kommt es an}

Wer reichlich Omega-3-Fettsäuren zu sich nimmt, der lebt herzgesund. Fisch ist eine gute Quelle dafür - die American Heart Association empfiehlt zweimal pro Woche Fische mit hohem Omega-3-FettsäurenAnteil, z.B. Makrele, Forelle, Hering, Sardinen, Thunfisch oder Lachs.

Allerdings scheint es auf die richtige Zubereitung anzukommen: Gekocht oder gebacken hilft deutlich mehr als gebraten oder gepökelt - so das Ergebnis einer Studie der Universität in Hawaii, bei der die Ernährungsgewohnheiten von über 200000 Personen mit dem Risiko eines Herztods im Verlauf von zwölf Jahren in Beziehung gesetzt wurden.

Ein weiteres Ergebnis der Studie: Speziell Frauen müssen nicht unbedingt Fisch im Übermaß zu sich nehmen. Ihr Herz profitiert offenbar mehr, wenn sie Omega-3Fettsäuren aus pflanzlichen Quellen beziehen, z.B. aus Sojaprodukten. Um auch diesen Effekt zu maximieren, wird in den USA jetzt Sojabohnenöl biotechnologisch optimiert: Statt Alpha-Linolensäure produziert die Sojabohne jetzt direkt Steari- donsäure. Dies erspart dem Menschen einen Stoffwechselschritt und erlaubt somit höhere Omega-3-Fettsäurenspiegel in den roten Blutzellen.

\section{RHINO CHILL}

\section{Der neueste Trend in der Reanimation}

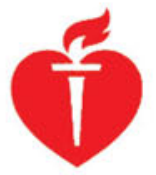

Das Gehirn kann nicht kalt genug werden, solange es nicht gefriert. Dies gilt nicht nur für den Notarzt, sondern auch für den Patienten mit Herzstillstand: Hypothermie verbessert die Überlebenschancen. Je früher die Kühlung, desto besser für den Patienten: Notärzte testeten jetzt eine mobile Nasenkühlung im Notarztwagen, wobei dem Patienten der Sauerstoff in Form einer Gasmischung zugeführt wird, welche die Nasenräume schnell auf $2{ }^{\circ} \mathrm{C}$ abkühlt. Das Prinzip funktionierte und war sicher. Sofern es innerhalb von zehn Minuten nach dem Kollaps zur Anwendung kam, schien es auch die Prognose zu verbessern: Die Überlebensrate stieg von $29 \%$ auf $59 \%$, diejenige ohne neurologischen Schaden von $18 \%$ auf $46 \%$ - so das Ergebnis einer Studie mit 200 Patienten.
WII SPORTS ${ }^{T M}$ UND WII FIT ${ }^{T M}$

\section{Aktive Videospiele beugen Adipositas vor}

Ein bisschen Sport ist besser als kein Sport. Um träge Kinder, Jugendliche und Erwachsene zu körperlicher Bewegung zu motivieren, sind aktive Videospiele wie Wii sports ${ }^{\mathrm{TM}}$ und Wii fit ${ }^{\mathrm{TM}}$ durchaus segensreich, wie jetzt auch wissenschaftlich belegt ist. In einer von Nintendo ${ }^{\mathrm{TM}}$ finanzierten, beim US-Herzkongress vorgestellten japanischen Studie war der Energieverbrauch der beliebten Videospiele vom Boxen, Tennis und Golfen bis hin zu Yoga, Aerobic, Kraft-, Resistenz- und Gleichgewichtstrainung erfasst worden. Ergebnis: 31 Spiele gingen mit leichtem ( $<3$ MET), 14 mit mittelstarkem (3-6 MET) Energieverbrauch einher. Zum Vergleich: Ein Erwachsener, der mit einem Tempo von $5 \mathrm{~km} / \mathrm{h}$ marschiert, verbraucht 3,3 MET. „Das Ausmaß der körperlichen Aktivität bei diesen Videospielen reicht aus, um Adipositas, Diabetes und metabolischem Syndrom vorzubeugen", bilanzierte Studienautor M. Miyachi vom Nationalen Institut für Gesundheit und Ernährung in Tokyo.

Jahrestagung der American Heart Association, Orlando/FL, 15.-18. November 2009

\section{NACHWEIS VON INFLUENZA A/ $\mathrm{H}_{1} \mathrm{~N}$}

\section{Schnelltests nicht geeignet}

Bei Verdacht auf eine Infektion mit der neuen Influenza $\mathrm{A} / \mathrm{H}_{1} \mathrm{~N}_{1}$ macht es wenig Sinn, einen Antigen-Schnelltest zu veranlassen. Das zeigt u. a. eine Studie der Uniklinik Bonn: Proben, in denen mittels PCR die Virus-RNA nachgewiesen worden war, wurden per Schnelltest nachuntersucht. Nur bei 16 der 144 Proben fiel der Schnelltest auf $\mathrm{H}_{1} \mathrm{~N}_{1}$ positiv aus.

Sogar bei Patienten, die wegen der neuen Grippe intensivmedizinisch behandelt werden, spricht der Schnelltest häufig nicht an. Von 20 australischen Intensivpatienten mit positiver rtPCR in Proben aus den unteren Atemwegen hatten nur fünf einen positiven Schnelltest auf $\mathrm{H}_{1} \mathrm{~N} 1$.

Emerg Infect Dis 2009;15:1662-64;

N Engl J Med. 2009;361:1925-1934

\section{VERHALTENSFORSCHUNC}

\section{Wie viel Haut soll Frau zeigen?}

Psychologen der Universität Leeds wollten eine der dringlichsten Menschheitsfragen lösen: Wie viel Haut soll Frau zeigen, um den richtigen Mann anzulocken? Für ihre Feldstudien suchten die Forscher Nachtclubs auf, bewerteten den Bekleidungszustand der weiblichen Gäste und maßen, wie oft diese von Männern angesprochen wurden. Die meisten Kon- takte konnten Frauen verbuchen, die 40\% Haut entblößten. Bei der Berechnung wurden Gesicht, Hände und Füße nicht gewertet. Entblößte Arme schlugen mit $10 \%$ zu Buche. Ein nackter Torso wäre als $50 \%$ gewertet worden. $50 \%$ ist aber des Guten zu viel, warnen die Forscher. Dies locke die falschen Männer mit möglicherweise unguten Absichten an.

So ganz nebenbei ermittelten die Forscher auch, wie Mann sein muss, um auf Frauen zu wirken. Am besten schneidet hier der absolute Durchschnittstyp ab: nicht zu dick und nicht zu dünn, nicht zu groß und nicht zu klein usw. Und Haut zeigen muss Mann auch nicht. Sehr beruhigend.

Behaviour 2009;146:1331-1348 